\title{
The Relationship of Risk to Rules, Values, Virtues, and Moral Complexity: What We can Learn from the Moral Struggles of Military Leaders
}

\author{
Kate Robinson ${ }^{1} \cdot$ Bernard McKenna ${ }^{1} \cdot$ David Rooney $^{2}$ \\ Received: 9 September 2020 / Accepted: 10 June 2021 / Published online: 17 June 2021 \\ (c) The Author(s), under exclusive licence to Springer Nature B.V. 2021
}

\begin{abstract}
Leaders are faced with ethical and moral dilemmas daily, like those within the military who must span from large-scale combat operations to security cooperation and deterrence. For businesses, these dilemmas can include social and environmental impact such as those in mining; and for governments, the social and economic impact of their decision-making in their response to COVID-19. The move by Western defence forces to align their foundational principles, policies, and "soldier" dispositions with the changing values of the countries they serve are starkly illustrative of challenges faced by all leaders. While admirable, such changes face the apparent contradiction of enhancing individual moral agency within a hierarchical organization that maintain enforceable codes of conduct. Ethical leadership theory provides aspirational goals, but lacks empirically based guidance on how to implement policies that facilitate values-based behavior. Using a discourse theory analysis of a moral dilemma vignette with Royal Australian Air Force personnel, this research identifies important aspects of agency and subject position that must be addressed if such policies are to succeed. These findings show that the potential contradiction can be addressed by acknowledging the contrasting tendency to bureaucratic process by leaders at upper levels, while lower-level leaders address moral issues by incorporating their subjectivity and making a conscious deontological choice between humanity and comrade loyalty.
\end{abstract}

Keywords Military $\cdot$ Virtues $\cdot$ Discourse $\cdot$ Agency $\cdot$ Values $\cdot$ Leadership

\section{A Leadership Dilemma}

Leaders and their organizations face increasing levels of risk and simultaneously demands from the community to become more ethical. An important aspect of this situation is to develop more ethical leaders with a sound set of values that direct their actions in ethical ways as they ameliorate risk. The escalation of risk related to climate change, food and water security, geopolitical instability, conflict, economic recession due to pandemic, and other forces have led many

Kate Robinson

cathryn.robinson@uq.net.au

Bernard McKenna

b.mckenna@business.uq.edu.au

David Rooney

David.rooney@mq.edu.au

1 University of Queensland, Brisbane, Australia

2 Macquarie University, Sydney, Australia organizations to set more rules in place and to support those rules with greater levels of bureaucracy. Potentially, a focus on bureaucracy and rules compliance hinders the opportunity to practice values-based leadership (VBL). Making values-based judgments and acting on them could lead to actions that transgress a rule. As we will show, a valuesbased leader cannot have all their actions prescribed within a set of predefined rules. In other words, VBL requires some level of rules independence if it is to work. This article explores the possibility of doing VBL in rules-based organizations that face significant risks. To do this we look at a military organization that wishes to shift to VBL. Arguably, the military faces greater challenges in adopting VBL than do civilian organizations and therefore put into sharper relief any barriers to doing VBL in rules-based organizations. We show that this sharper relief makes clearer what the problems are and how they may be dealt with.

Military leaders face ethical and moral dilemmas daily that span the conflict continuum from large-scale combat operations to security cooperation and deterrence. Although 
codes of conduct are provided to guide behavior within all organizations, military leaders are continually faced with ethical and moral dilemmas for which codes provide insufficient guidance on their own. This is even more so in the ambiguous conditions faced by the modern soldier (Tripodi $\&$ Wolfendale, 2012), which require value judgments. This was explicitly stated in 2011 by the Australian Chief of Defence Force (CDF), Air Chief Marshall Angus Houston, who called for values to guide leadership: "[T]o establish and maintain the right culture, a value-based culture...Values should define the way the leadership in the organization behaves. If you can establish the right culture in your organization, goals are much easier to achieve" (Leading the Australian Defence Force, p.153). Despite its admirable intent, Houston's call raises a fundamental question. Can a traditional, hierarchical, rules-based organization create a values-based culture built upon values-based leadership?

A values-based culture is an amalgam of organizational values, ethical codes, and personal morals that motivates values-based behaviors [VBB] and ethical decision-making. But is this workable? To answer this, we will firstly clarify how morality, values, and ethics can be usefully defined. We then problematize values-based behaviors, then specifically consider this within the military context. Examining the military context is important because it throws into sharp focus the challenges of bringing virtue-based cultures and leadership to all organizations that are rules-based in the face of uncertain and volatile contexts or because of their need to avoid causing harm to individuals, groups or the environment. From this review, we will identify the impediments to achieving VBB, the relations of power impacted, and agency as relevant concerns. Our vignette-based method has provided significant data that are analyzed using a discourse analytic approach. Our discussion leads to useful considerations for all organizations in which there is potential to cause significant harm and who wish to enact values-based leadership.

\section{Morality, Values, and Ethics}

Underpinning our approach to understanding morals, values, and ethics is Aristotelian virtue ethics and practical wisdom. Morality refers to our normative beliefs about what is right and wrong. Moral judgments, according to Bartels et al., (2015, p. 479), "often concern courses of action that entail some harm, especially loss of life or other physical harm." According to Haidt (Graham et al., 2011; Haidt, 2001), our moral intuitions are related to five moral foundations, all of which have an underlying biological base: care, fairness, loyalty, authority, and sanctity/purity.

Values, on the other hand, are not necessarily moral. Schwartz (1992) defines values as guiding principles for people or groups that underpin and explain human decisionmaking, attitudes, and behaviors. Values, according to the philosopher Boudon (2001, p. 8), are likely to be grounded "under the effect of psychological, sociological or biological forces." Schwartz (1992) identifies ten basic motivational values that are recognized across societies. Five of these basic values concerning positive relations of self to others (universalism, benevolence, tradition, conformity, and security) are considered by participants as "moral", whereas the other five values expressing self-interest (power, achievement, hedonism, stimulation, self-direction) are not considered "moral" (Schwartz, 2007). This suggests that there are motivational values held by individuals or groups that are not necessarily moral because they are not altruistic.

Finally, ethics involves explicit explanations about what is appropriate in particular situations (Hartman, 2007), and tends in organizational life to be codified in some form that specifies appropriate conduct "designed to prevent damage or avoid injury" (Cameron, 2011, p. 27). However, by specifying the right course of action in various situations, codified ethics is at odds with the virtue-based Aristotelian notion, which understands ethics as not only an explanation of what to do but also of why. Derrida (1992, p. 24) goes further, arguing that a "decision that didn't go through the ordeal of the undecidable would not be a free decision, it would only be the programmable application or unfolding of a calculable process." In other words, ethical codes take away the moral dimension of making judgments because free will is not used, only compliance. Virtue ethics requires, ethical and moral analysis in discerning what is the right thing to do. Complicating ethical compliance is that the truly ethical (virtuous) citizen, then, "must, somehow, negotiate a path between contradictory, irreconcilable, and incommensurable responsibilities and accountabilities" using higher-order ethical analysis (McKernan, 2012, p. 259).

Having now defined these three terms, we need to redefine the question by referring to a virtue-based organization rather than a value-based organization.

\section{Agency and Subject Position}

This paper uses a Foucauldian discourse-based approach to analyze its interview data because this allows us to investigate issues of agency and subject position, which impact on organizational behavior. That is, from a Foucauldian perspective, human agency is located in a power matrix described by subject position and discourse (this is described more fully in Coole, 2007).

Agency is a contested term in the social sciences ranging from the extremes of the willful actor to a relatively powerless determinism (Abdelnour et al., 2017). A useful initial definition is provided by Burkitt (2016) who says that agency 
relates to people "producing particular effects in the world and on each other through their relational connections and joint actions" (p. 323). Our view of agency within organizations is that individuals are "purposive actors" whose range of possible actions is determined by "the constraining and enabling contexts of action" (Emirbayer \& Mische, 1998, p. 964). Significantly, agency has a temporal and relational element because organizational structures transform over time and are reproduced in social interaction within an organization. This view of agency is consistent with Giddens (1979, 1984) and Archer (2003) who incorporate reflexivity in their theory of agency. Thus, human agency is an embedded process of social engagement, through discourse, informed by the past yet oriented towards the present and the future. Significantly, a person can envisage alternative possibilities and contextualize the past habits and future events or projects within possibilities of the present time (Emirbayer \& Mische, 1998).

Turning now to subject position, we propose that a person's moral and social identities, which are closely related, largely create their subject position, or subjective orientation. According to McAdams (1996), identities are formulated by individuals in relation to the discursive practices and resources within their environment. This suggests that individuals can have multiple subject positions depending on the discursive practices of the environment they are in. In this way the subject is seen as a construct shaped, but not determined, by complex relations between knowledge, tacitly or explicitly describing the way things get done, and power, the degree of agency within a codified, disciplinary organization (Foucault, 1982). The organizational member, acculturates, or accommodates by adapting their values, attitudes, and patterns of behavior (Casey, 1999). An organizational member adapts to varying degrees to align the interests of their identity with that of the organization if they are not to suffer dissonance.

\section{Values-Based Leadership in a Military Context}

Although the four main foundational values-based leadership theories-transformational, authentic, servant, and spiritual-espouse values-related characteristics such as self-awareness, ethics, authenticity, motivation, and inspiration (Bass \& Avolio, 1990; Gardner et al., 2011; Paarlberg \& Lavigna, 2010; Sweeney \& Fry, 2012), they do not show how to embody these characteristics to deliver this values-based leadership. Nor do these leadership theories focus on virtuous leadership (McKenna \& Rooney, 2019, incorporate virtues into their notion of wise leadership).
This raises the question of how, indeed if, it is possible to do virtuous leadership in the military. To answer this question, we must first understand two important characteristics of military leadership that distinguish it from civilian leadership.

The first difference is the mandatory and legally enforceable subordinate compliance of military practice. Military personnel in this study are governed by Rules of Engagement (ROE), Laws of Armed Conflict (LOAC), and the Defence Force Disciplinary Act (DFDA). These enforceable rules are reinforced by daily discursive and material practices framed by policies and procedures that are set down by legislation, ADF codes, and military law. These rules govern diverse topics such as finance, flight manuals, and standard operating procedures.

The second significant difference is that military activity involves deliberate and accidental human death. Military personnel face in extremis situations because the outcomes are "characterized in terms of hurt or healthy, dead or alive" (Kolditz \& Brazil, 2005, p.6); that is, soldiers work in a "setting in which actors face persistent existential threat" (Buchanan \& Hällgren, 2019, p. 153). What differentiates in extremis leadership from other forms of leadership is that when operating in situations of imminent physical danger, followers believe that their leader's behavior influences their survival (Kolditz \& Brazil, 2005). Importantly, soldiers are "willing to accept coercion from above providing it was in the general interest" (Fraher \& Grint, 2018, p. 396). They willingly place themselves in higher personal risk situations, even selfsacrifice, to perform their duties (Hannah et al., 2009). Furthermore they may self-sacrifice if necessary as part of their duty and commitment to the organization and ethos.

In extremis leadership aligns with a values-based form of transformational leadership in life-threatening situations (Kolditz \& Brazil, 2005). The expectation of exemplary ethics and leadership within in extremis combat situations is more complex in the blurred conditions of contemporary warfare. As Fisher et al. (2010) warn: "in a context where excess violence occurs frequently and with ease, the development of a culture of violence may occur ... the lack of taboos and prohibitive rules found in war may allow leaders to rationalize behaviors that would be unacceptable in a different context (pp. 106-107). For example, in 2016, an Australian Special Operations soldier amputated the hands of a dead Taliban insurgent putatively for biometric identification. This led to public allegations of values 'drift' occurring within Australia's elite special forces. This Special Forces corporal "followed orders" in an in extremis situation, having been told that biometric 
identification was a tactical necessity required by the special forces. Yet mutilation of an insurgent's body, contravenes the Geneva Convention, which says "search for the dead and prevent their being despoiled". Within this intense environment the expectation of ethical leadership created an obvious tension.

But not all military leadership occurs in armed conflict: in fact, mostly it does not. There is a continuum of military engagement that includes large-scale combat operations, crisis response and limited contingency operations, as well as military engagement, security cooperation, and deterrence. For the ADF, this continuum ranges from military operations in Afghanistan, and Iraq to delivering foreign aid to countries stricken by natural disaster such as the Solomon Islands and Somalia, as well as responding to domestic massive bushfires and the COVID-19 pandemic. Complexity and ambiguity for military leaders increases when, within seconds, the pendulum swings across the continuum to military operations. For example, an aid or peace-keeping mission might confront acts of violence forcing coalition forces to respond to such threats (Tripodi \& Wolfendale, 2012).

This increased complexity in military leadership is caused by the need to make high-level decisions within ambiguous environments that include military, economic, and social factors (Galusca et al., 2010). More specifically, in combat situations, leaders need to have a well-developed capacity for situational awareness in which recognition, interpretation, and prediction of an event are essential elements in decision-making (Endsley, 1988; Kaber \& Endsley, 1997). This moral and ethical intensity makes the military a useful site to research the complexities of enacting virtuous leadership.

This is because in this liminal zone of ambiguity, virtuebased leadership and culture is most tested. The more uncertainty for a leader, the higher the risk of the decision-making process (Galusca et al., 2010). According to the soldier who mutilated the Taliban insurgents in response to instructions, there was apparently no uncertainty: he followed orders. This incident highlights that in today's combat environment, military personnel are more likely to be faced with ethical issues because their operations involve counterinsurgency, nation-building, and asymmetric warfare (Reed et al., 2016). Therefore, how leaders determine risk and the military effectiveness of an outcome will compound the complexity of the decision-making process and require more situational awareness. At a lower level of intensity, similarly complex and uncertain environments also test business leaders.

\section{Embodying Virtue}

Leadership research provides little guidance on how to embody virtue-based ethical leadership (Rooney et al., 2021). The relatively unknown concept of conation provides a bridge to embodiment of ethics. Whereas motivations and intentions are feelings, conation is the impulse to behave in particular ways that respond to those feeling (Gerdes \& Stromwall, 2008). Although ethical processing takes place, this cognitive process depends on an individual's personality and other traits (Trevino, 1986) and not just on ethical cognition (Hannah et al., 2011) to be enacted. Because the embodiment of virtues must include ethical cognition and moral conation, an effective model of moral capacities must address moral cognition, 'gut-based' moral responses, and moral conation. When an individual's moral sensitivities and motivations conflict with their organization's it may prove difficult for leaders to gain willing consent. This is where serious tensions and contradictions can occur.

Conation and judgment are adversely affected by the ambiguity of combat situations, stress, and repeated exposure to these conditions. We know that stress "lead[s] decision-makers to close on decisions prematurely, following incomplete and non-systematic review of alternatives"; that when processing large amounts of information under time constraints, "practitioners resort to ever simpler modes of information processing, in which alternatives are not explored"; and that stress predisposes people to more risky decisions (Ryus \& Baruch, 2018, p. 658). While this occurs at the cognitive level, stress detrimentally affects ethical decision-making. For example, increased cortisol often accompanies egoistic decision-making (Starcke et al., 2011), and "stressful conditions have been shown to decrease the participants' consistency between their beliefs and their actions" (Leder et al., 2015; Ryus \& Baruch, 2018, p. 658). This ambiguity and over-exposure were used to explain alleged war crimes by Australian SAS in Afghanistan by a former SAS commander war veteran, now Federal Parliament member, Andrew Hastie. He claimed that being entrenched in a highly ambiguous complex environment for three or four tours blurs the lines and blunts moral sensitivities. This leads to the question of how to address ethical dilemmas created by giving individuals the agency to make decisions and to understand the dynamics of their ethical conation within an ambiguous environment.

\section{Method}

\section{Procedure}

1 https://ihl-databases.icrc.org/applic/ihl/ihl.nsf/Comment.xsp? action $=$ openDocument $\&$ documentId=7BDA3DBA22F 405 ACC 125 7F15004A99BA.
This study used a vignette approach to investigate values-based leadership in dealing with an ethical dilemma. Vignettes are 
Table 1 Participant Profile Matrix

\begin{tabular}{|c|c|c|c|c|c|c|c|}
\hline \multirow{2}{*}{$\begin{array}{l}\text { Category } \\
\text { Gender }\end{array}$} & & \multicolumn{2}{|l|}{ Pilot/ACO } & \multicolumn{2}{|l|}{ Engineer } & \multicolumn{2}{|c|}{$\begin{array}{l}\text { PCO/Logistics/ } \\
\text { Security/Medical }\end{array}$} \\
\hline & & Male & 14 & Male & 7 & Male & 3 \\
\hline & & Female & 1 & Female & 2 & Female & 4 \\
\hline \multirow[t]{3}{*}{ Rank } & & Junior & 5 & Junior & 7 & Junior & 5 \\
\hline & & Senior & 2 & Senior & 1 & Senior & 2 \\
\hline & & Executive & 8 & Executive & 1 & Executive & 0 \\
\hline Total & 31 & & 15 & & 9 & & 7 \\
\hline Percentage & $100 \%$ & & $48.4 \%$ & & $29 \%$ & & $22.6 \%$ \\
\hline
\end{tabular}

well established as a means of creating a discussion about beliefs and values (Hughes \& Huby, 2012; Mah et al., 2014). Three hypothetical combat-related vignettes were generated by asking senior serving personnel with combat experience to provide an incident from current Middle East operations. From those provided we selected vignettes that would be likely to challenge the participants' capacity for values-based leadership within a volatile and complex situation where ROE and LOAC applied. Participants were prompted through open-ended interview questions to respond in a way that involved making a judgment on critical life and death situations.

To ensure authenticity and reality, four vignettes were created to deal with two contexts (air and ground) from each of four vantage points: 1. Pilot/Air Combat Officer (ACO) on a combat mission, 2. Security, Logistics, Engineering, or Medical members conducting an armed escort mission, 3. the unit commander, and 4. the senior unit commander (Appendix 1). Based on their rank and job category, participants were provided with the same relevant vignette (air or ground); however, the scenario questions presented were germane to their rank and position. To enhance warfare authenticity, participants were given limited information and a short time frame in which to 'act.' Though the dilemma questions differed to make them relevant for each of the rank structures, they elicited participants' perceptions, beliefs, and attitudes and the reasons underlying their judgment (Križ \& Skivenes, 2013; Smithson, 2000).

\section{Participants}

Interview data were collected from 31 respondents selected from various job categories including pilot, air combat officer (ACO), engineer, security, intelligence, logistics, administration (PCO) and medical. This cross-section of the Royal Australian Air Force (RAAF) provided a sample size enabling deeper analysis. The sample included executive officers $(\mathrm{N}=9)$, senior officers $(\mathrm{N}=5)$ and junior officers $(\mathrm{N}=17)$, both male $(\mathrm{N}=24)$ and female $(\mathrm{N}=7)$. Table 1 illustrates the demographic data of participants.

All interviews were tape-recorded and transcribed verbatim to provide a corpus of 32,146 words.

\section{Validity}

To ensure credibility and trustworthiness in the findings and conclusions, a number of strategies and measures were undertaken using recommendations from Sandberg (2005), Alvesson (2003), Lameck (2013) and Gregory (2014):

- Data collection validity was ensured by relying on the verbatim transcripts of all interviews. This ensured that all findings could be verified and substantiated.

- Transgressive validity was achieved through consciously looking for differences or contradictions by interpreting each of the transcripts then assessing each one with an alternative view till an optimal understanding and interpretation were achieved.

- Communicative validity was ensured through consistent interview protocols including allowing respondents to elaborate and substantiate responses.

- Sampling validity was achieved by ensuring a proportional representation of rank, gender, job category and location across the RAAF. The response rate for the vignette was $100 \%$ with all respondents participating.

\section{Analysis}

Our method, informed by Putnam's (2015) post-structural discourse theory, analyzed the data to seek out discourse attributes of knowledge and agency. This incorporates Foucault's (1971) approach to discourse analysis (DA) that examines the power-knowledge relationship, including implied enthymematic assumptions, to identify conformity and resistance. The analysis sought to identify tensions, contradictions and paradoxes (Wodak \& Meyer, 2009). The method is also hermeneutic as the level of analysis moves successively from surface level to the deep discursive level to provide an interpretivist analysis (Cavana et al., 2001; Heracleous, 2006; Hudson \& Ozanne, 1988).

In this study, Leximancer (Computer Assisted Qualitative Data Analysis Software) was used to provide inductively derived concepts (groups of near-synonymous words) 


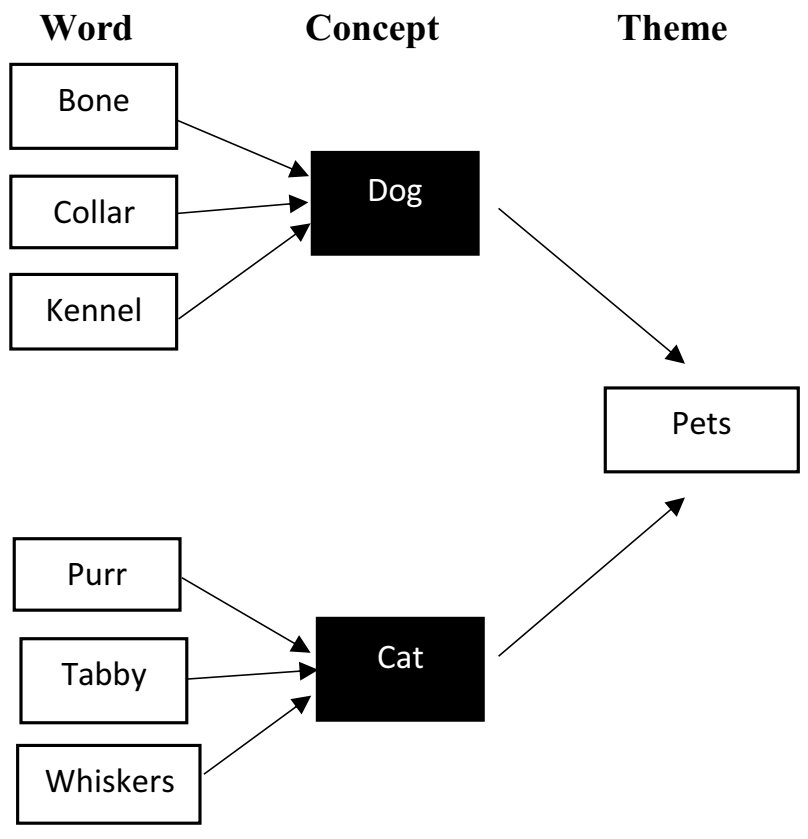

Fig. 1 Model of Leximancer Process

enabling the primary researcher to identify related concepts (axial coding) and themes (theoretical coding) that may not be immediately evident through manual data analysis. Themes and concepts generated by Leximancer were further interpreted to ascertain how they aligned with respondent's agency and subject position. Leximancer uses a process that is similar to Grounded Theory data coding that typically uses open coding, followed by axial coding, and finally theoretical coding. Leximancer, however, analyzes the data to (1) identify semantically important words, then (2) analyzes semantically related words that collectively form a concept, and finally (3) it groups related concepts into themes. Figure 1 illustrates the Leximancer software process of identifying words, concepts, and themes.

The figure indicates that the co-occurrence of the words (bone, collar, kennel) is about the concept, dog, and that the words purr, tabby, and whiskers are parts of the concept, cat. Leximancer then creates the theme by assessing how closely each concept clusters with other semantically related concepts. Pets as a higher-level abstraction thus includes dog and cats.

In the initial analysis stage, the transcripts were sorted into respondents' three rank levels and submitted to three rounds of inductive analysis using Leximancer software. The second stage moves from computer-based analysis to manual analysis. This is because, while Leximancer delivers a purely inductive analysis of the data's characteristics in the form of concepts and themes, the researcher must then interrogate this level of data as the basis of their interpretive analysis. A concept is a group of words with similar meanings within the corpus, provided inductively by Leximancer: e.g., information could potentially include data and information. The researcher's role is to look particularly at the most frequent concepts by returning to their location in the interview text to determine their meaning in the context in which they are used. From this lexical level of analysis, the researcher then interprets meaning in discursive terms (the move from text to discourse analysis). This occurs in an iterative process of interpretation to develop discernible and credible discourses. Once these discourses are identified, we can then compare the subject positions and dominant concepts and themes associated with different rank levels.

To counter the criticism that the analyst will simply interpret findings from a preconceived perspective (Widdowson, 1995, 1998), our process involved an initial hermeneutical interpretation of texts (Bell, 2011) undertaken by the lead researcher and then critiqued by others. Initially, the findings were presented to her co-researchers who made suggestions and challenged categorizations used to analyze and interpret the data. The findings were also presented in a refereed paper to a distinguished international conference and finally it was critiqued by two academics not involved in the study. Our analysis begins with the interpretation of the initial inductive textual analysis provided by Leximancer.

\section{Results}

The discourse analysis framework identified dominant concepts, discourses, and themes related to values as well as subject positions that are unique to each rank category. The framework also highlighted potential inherent subject-role conflict. The frameworks of leadership in each of the officer rank categories are analyzed with initial findings illustrated in Table 2.

Although the three rank categories shared three concepts (rules, decision, information), significant differences occurred at the level of themes, discourse, and subject position. At the thematic level, executive and senior officers share decision, rules and information, whereas the junior leaders' emerging themes were decision, collateral, and situation. Closer analysis showed that this difference was based on junior officers' focus on collateral (damage) which aligns with their differing discourses of risk and values.

Further differences were highlighted with respondents' subject positions. The executive officers aligned with their rank, adopting a more bureaucratic and organizational subject position. While the senior officers also adopted an organizational subject position (professional; organizational reputation), the presence of the parent/gender subject position alerted us to potential subject position conflict. The junior officers shared the professional subject role but also 
Table 2 Discourse, Themes, Concepts and Subject Position from DA

\begin{tabular}{|c|c|c|c|c|c|}
\hline \multicolumn{4}{|l|}{ Values } & \multicolumn{2}{|l|}{ Leadership } \\
\hline & Discourse & Themes & Concepts & Subject Position & Conflict of Subject position/role \\
\hline Executive & $\begin{array}{l}\text { Organizational } \\
\text { Legal Framework } \\
\text { Rules }\end{array}$ & $\begin{array}{l}\text { Decision } \\
\text { Rules } \\
\text { Information }\end{array}$ & $\begin{array}{l}\text { Rules } \\
\text { Decision } \\
\text { Information }\end{array}$ & $\begin{array}{l}\text { Bureaucratic/government } \\
\text { Professional } \\
\text { Organizational/Rank }\end{array}$ & $\begin{array}{l}\text { Bureaucratic vs Organizational } \\
\text { (Responsibility vs account- } \\
\text { ability) }\end{array}$ \\
\hline Senior & $\begin{array}{l}\text { Organizational } \\
\text { Legal Framework } \\
\text { Rules }\end{array}$ & $\begin{array}{l}\text { Decision } \\
\text { Rules } \\
\text { Information }\end{array}$ & $\begin{array}{l}\text { Decision Rules } \\
\text { Situation } \\
\text { Information }\end{array}$ & $\begin{array}{l}\text { Organizational/reputation } \\
\text { Professional } \\
\text { Personal (parent/gender) }\end{array}$ & Organizational vs Personal \\
\hline Junior & $\begin{array}{l}\text { Organizational } \\
\text { Rules } \\
\text { Risk } \\
\text { Values }\end{array}$ & $\begin{array}{l}\text { Collateral } \\
\text { Decision } \\
\text { Rules }\end{array}$ & $\begin{array}{l}\text { Information } \\
\text { Decision } \\
\text { Rules }\end{array}$ & $\begin{array}{l}\text { Professional } \\
\text { Military } \\
\text { Personal (parent/family) }\end{array}$ & Professional vs Personal \\
\hline
\end{tabular}

revealed potential subject misalignment with the presence of the parent/family subject role.

Alerted to this potential dissonance among ranks, our analysis at the discursive level led us to identify various discourses and their affiliated subject position. Significantly, the Executive and Senior Officers shared discourses (organizational, legal framework, rules), whereas risk and values were present in the junior officers' discourse. This discoursesubject analysis is now elaborated.

\section{Executive Officers}

Interpretive analysis revealed three clear discourses: organizational, legal framework, and rules (see Table 2). The DA showed that the knowledge sources that the executive officers drew from were primarily operational practice based on ROE that aligns with the discourses of rules, legal framework and operational practice. This was further supported by the Leximancer analysis where two central themes of rules and information emerged. The concepts, drawn from the themes that executive officers most identified with, were information, decision, and rules.

Closer contextual analysis of this group's corpus showed that they placed considerable importance on ensuring there was public confidence in the organization's reputation. This aligns with the finding of the lexical marker of organizational and bureaucratic discourse [proper investigation] for this group:

[I] think public confidence is certainly a factor that you need to work through... I think you can restore public confidence um, by conducting a proper investigation on the rules of engagement shortfalls.

The term 'proper investigation' draws on legal discourse that creates a norms-based approach to justify an organizational response that is conscious of societal judgment. This standardized legal procedure provides a relatively comfortable order for executive officers that may not be available to those physically (bodily) engaged in warfare. Unintended civilian death is attributed to inappropriate strategic setting:

[Y] ou can fly and comply with rules of engagement but if your strategic intent is not to take civilian lives and, and you see that occurring regularly, even if you're complying with rules of engagement, then you haven't got to the strategic setting right for the campaign.

The undesirable outcome despite compliance with ROE is discursively overcome by technocratic discourse that classifies loss of civilian lives in a way that 'depersonalizes' the victims to occlude human suffering (McKenna \& Graham, 2000, p. 224; McKenna \& Waddell, 2006). According to this executive, the strategy can simply be 'adjusted':

[A] series of events... might then begin a thought for how we go about our rules of engagement, but has the fight changed as to where the rules of engagement need to be adjusted... That would be a recommendation to government; it would go through an entire government process.

Thus, at the most senior executive level, agency is abandoned (note the absence of humans in this statement) to circumvent the dialectical tension by shifting the solution from an ethical, humanitarian framework to a technocratic process. This lack of personal agency is further weakened at the executive level by using the technocratic device of 'aggregated advice' that actively eliminates the commanders' moral responsibility:

[I] t's not about a commander...sitting in a big leather chair with a monocle going, "no, not going to investigate that one, yeah, we'll investigate that one". It is... extremely sophisticated and the number of people involved in providing advice to the commander is substantial and deep...it is not based on that individual commander's personal view; it is on an aggregated set of advice. 
The individual agency of the commander is eschewed in favor of a complex, collegial, bureaucratic process that is not available to those in the urgency of battle. The decision is socialized to be dealt with by experienced expert group opinions rather than individual judgment.

For executives, the ambiguity of accountability is resolved through a deliberative legal and bureaucratic discourse in which individual values-based judgments are secondary. For this executive, the 'layers of command' and 'hierarchy' resolve the ethical dilemma:

[T] his is why in the end you have layers of command... this is why we actually have a hierarchy because, in the end, someone's held to account for that individual's decision down there.

This executive's use of 'command instruments' and 'duly authorized' characterizes the technocratic, organizational, and legal discourse that is deliberative and expert but devoid of a values jurisprudence. Its technocratic character implies an objectivity without a moral dimension. Below, the hierarchical discourse markers, 'layers of command' and 'command instruments' are consistent with a techno/bureaucratic discourse of being 'duly authorized', and having a 'systemic problem':

[I]f the people in the field are duly authorized under rules of engagement, the commander is duly authorized under command instruments to make those judgements.

[A]s it escalates and you have a systemic problem potentially ...

Furthermore, rules-based organizations require sanctions to ensure conformity:

[I]f you did an investigation and there were individual shortfalls at play um, then that would naturally lead into a court-martial type decision or some disciplinary decision.

The word 'naturally' assumes the inevitability of sanction when a 'shortfall' is determined. Technocratic discourse classifies actions in a particular way that allows a certain process to ensue (McKenna \& Graham, 2000). Thus, moral and ethical decisions are rendered as processual; the discourse is decidedly legalistic and punitive, more aligned with transactional leadership. Ultimately, this legal-technocratic process draws its authority from 'societal values', which are enthymematically implicit:

[O]ur values and our trust from the public is based on us acting in accordance with a set of rules and aligned with the values of our society

If so, then values-based leadership does not imply individual agency based on a personal moral code. Rather military personnel need to align their values with societal ones; however, that may be construed. Failure to comply with societal values at an individual level triggers a technocratic process while at the corporate level, executive responsibility is to re-align strategy.

It was clear in the executive officer analysis that these leaders located themselves in professional, bureaucratic and organizational subject positions that allowed them to defer agency to another level of authority. In terms of material actions, they largely follow codes and procedures, but mostly take responsibility only for altering rules or strategies and establishing deliberative processes. They therefore oriented themselves to a detached processual perspective that draws its moral and ethical foundation from public confidence based on 'societal values.'

\section{Senior Officers}

Analysis of the Senior Officer's corpus led to the identification of rules and information themes (Table 2). However, this group provided more nuanced responses by raising gender and professional affiliation concerns in determining how they would respond. Although executive and senior leader groups shared three discourses (legal, rules, and organization), tensions, contradictions, and internal conflict were more evident in the senior leader group. They shared with the executive group the same knowledge sources, which were rules, policy, and laws. The central concepts that were most salient for this group were decision, information and rules.

The senior leaders were more inclined to incorporate a wider range of discursive elements including morality, rules, law and the operational situation in their reasoning. This was shown in the following two responses by a male pilot:

[I]f they've made a reasonable decision based on what they saw at the time, then you've got to support them in that.

This statement displays strong agency, delimited by the legal requirement of a 'reasonable decision'. Although displaying personal agency, and referring to values, he expected the higher ranks to 'pony up' by supporting his right to make the judgment:

[S]olid decisions made on information on hand at the time in accordance with the rules of engagement of the organization that we supported... and be hopeful leadership would actually pony up to those values and support people who do those things.

This would seem to be more in accord with Houston's ideal that an organizational values-based approach must allow for individual agency. 
The subject position of most senior officers was shaped by their experiences within their various professions as engineers or doctors, which impacted on their sense of agency. Another consideration was the influence of private or family life and gender identities that intersect with their organizational identities. For example, a medical professional drew on her parental and professional identities, confessing that they caused internal conflict as she struggled with the notion that children may be innocent. The related emotions conflicted with her organization's requirements and her own personal values. These factors were, in turn, tempered by her military experience. Her multiple subject positions: health provider, parent, military commander, and female, were all salient to her. The following statement illustrates her internal dialectic:

[A]s a healthcare provider in a military organization, this is always the challenge...to see children...killed in these situations...children are always innocent and therefore I could easily be biased against the actions of the Australian Army. But having been in the military long enough, I guess and seeing what all...levels of the population are capable of doing, you start to lose that bias. But then there's that internal conflict of, do I really want to be part of this... is this keeping with my personal values to be involved in an organization where these are very real scenarios.

The use of "I" is a clear personalizing lexical marker mostly absent in the executive officers. Further questioning of her responses reveals her nuanced consideration of ROE which for the executive officers was largely a procedural matter. This respondent draws on personal values and empathy, but also understands that her defence role is possibly at odds with the wellbeing of others. She clearly states that her two allegiances, military and medical, are the source of the tension she faces in leadership. Aligned with her experience as a parent, she underwent internal tension, a possible contradiction within her own values; consequently, she challenged the authority of ROE as a procedural mechanism.

Another female medical respondent, from her military and professional subject positions, also struggled with having to make a decision as a commander because it potentially conflicted with her medical professional ethics:

[I] face tensions when I'm expected to work outside the environment my skillsets have me for... [M]y first role to them as a doctor is their emotional and physical wellbeing. And I can't do that if I'm the person that's reaming them out.

The duality of subject positions creates an unresolved tension between values, rules, and her sense of agency as she conatively commits to an act.
Also contrasting with the executives' processual orientation, a male pilot, a person who actually makes this decision in combat, used the concept of the reasonable person and identified contextual factors as important:

...[I]f they've made a reasonable decision based on what they believed at the time, then you've got to support them in that...you've got to understand this person has already been through an extraordinary amount, to put them through something more when there's... no strong evidence to suggest that they've done anything wrong would be very difficult to support.

This officer acknowledges the need for humanity in the process and supports agentive judgment that is 'reasonable' in the context of what the person 'thought or felt' was the case. This is clearly at odds with the executive officer view because it explicitly assumes that the rules are open to interpretation. Another male pilot also took a strongly agentive approach based on a sense of morality:

[T] hat would then come down to what you thought was right or wrong...my first thought would be what's right and wrong.

For these pilots, agentive judgement based on personal values ignores the ROE which in any case they see as open to interpretation based on the contextual factors and the judgment of a reasonable person. However, not all senior officers took this approach. A ground defence officer revealed strong faith in process, even if it involved a court martial:

... [s]o I think in this instance I would certainly send the member to a court martial...sending him there doesn't imply guilt or otherwise, it just gives us the opportunity to explore that... I'd have faith in the system to come out with the right answer...I'd do it would just to protect the reputation of the organization so we are seen to do the right thing.

Overlooking any consideration of the personal stress for a court-martialed officer in an 'unbiased system,' like the executive officers, he uses public perception as a moral foundation. This may be simply for instrumental reasons (the RAAF avoids unfavorable public attention) or for normative reasons (society provides the norms of ethical action). Nonetheless, it is a rules-based approach in which military judgments are evaluated by external norms, not virtue-based agency.

In summary, there was clearly a higher level of dialectical tension among senior officers compared to the executive officers. While still acknowledging the role of systems and rule-based procedures, there was greater nuance created by considering context, assuming some 'reasonable' form of evaluation, and considering the humanity of the officer involved. Although the data are limited, it seems that gender 
and professional identity may be relevant variables of potential conflict with organizational identity and commitment to the 'rules.' Notwithstanding this, their decision-making is still underpinned by the rules by which the leaders need to adhere. On balance, the senior officers' leadership tends to be rules-based, but significantly more attenuated than the executive officers.

\section{Junior Officers}

It was evident in the surface level analysis that the junior officers' discourses were primarily about organizational rules, risk, and values. However, closer textual analysis identified a strong focus on the value of life. The lexical markers of this values-based discursive orientation were evident in the following themes: people (children, school, collateral) and the inherent moral complexity in modern warfare (soldiers, insurgents). Another significant discursive feature that emerged from the Leximancer analysis (information, time, decision, and situation) are features of situational awareness in decision-making. Importantly, junior officers are more likely to have recently been on the 'frontline' where quick life and death decisions are made. Although incorporating ROE, LOAC, and standards of conduct in their responses, junior officers were far more likely to incorporate morality and values discourses. Two interviewees referred directly to the material and human elements of engagement:

...[b]ecause we're going through school whether you're going to perhaps have some collateral damage...destroying either school or children um or anyone else around there that is innocent... (Male pilot) $[\mathrm{H}]$ ow many insurgents, how many school children are present, or how many Australian soldiers... if you said that was all equal, then this is where it gets hard. (Male ACO)

Another pilot included a vital moral principle about the primary importance of human life, which could be considered as a sacred value.

[T] hese are the ramifications that people live with all the time and just because its children makes it worse but ah, any life is important. (Male Pilot)

Although the first two respondents drew on military organizational discourse ('collateral damage'; 'insurgents'), they also recognized the humans involved ('school children'). That children were involved heightened the moral tension. In acknowledging the humanity of those they may kill, they eschewed technocratic discourse to deal with it as a moral, not procedural, issue. This is evident in the last respondent adopting a universal principle about human life with the consequences that 'people live with all the time' to justify his action.

The following female intelligence officer relies on a 'reasonable person' legal principle in making a consequentialist moral judgment to justify the action to herself:

... [i]n the context at the time as a reasonable person" rule...I value the lives of my personnel over the life of someone else outside of that organization ... there's a tension.

This respondent's interpretation of the 'reasonable person' rule is strongly affected by her military subject position that demands organizational loyalty, an overriding value instilled in soldiers demanding moral and solidarity compliance. As with the previous three respondents, the humanity of those whom they may kill is acknowledged ('child[ren]').

As the respondents deal with the moral implications of their action, those involved in the physical military action need to be situationally aware. This situational awareness, a cognitive function, is vital at two levels: making a tactical and moral judgment to act or not:

[I] know that in that split second, I would probably also hesitate and wait and see how it presents. ... [T] here are so many variables ... The hesitation part of it ...kids running towards them, pulls out what looks like a mobile phone.... but it's a kid.

This dual cognitive role of situational awareness is evident: 'so many variables' to identify in the immediate environment and assess tactically. This requires focused cognitive functioning: because 'it's a kid,' the judgment is not only tactical, but also moral. For this person, to have 'shot a kid' requires moral justification not needed when shooting an 'insurgent':

$[\mathrm{H}]$ ow do you live with yourself after you've shot a kid...that presumes that... you're acting within the ROE...my mission set which is to make sure my convoy gets to where it needs to go and that my personnel are protected. I'll protect them at all costs.

On balance, adopting a utilitarian approach, her moral judgment is guided not by a universal principle of respecting human life [see male pilot quote], but loyalty to one's comrades, or solidarity: that is, the Loyalty foundation overruled the Suffering foundation as in Haidt and Joseph's (2004) moral foundation theory. Her decision rests ultimately on forensic technical knowledge moderated by a hesitation based on moral grounds. This form of moral evaluation is also evident in another junior officer, a female ACO, who evaluated the conundrum in terms of the differential value of lives: the life of a child or an Australian soldier: 
...[s]o who's life is more valuable...because you're valuing, picking the life of the children over the lives of the patrol...I have an inherent...loyalty to them...

The intelligence officer and ACO clearly prioritize loyalty to their comrades. This solidarity principle in choosing the life of a comrade over an uncertain enemy-child is more complexly elaborated compared to the executives who simply comply with the legal application of ROEs.

Another dimension, the subject position, was more explicit in the junior officer responses. This ACO's moral orientation is conflicted given the primacy of her family and parental roles:

... [b]ecause my brother deployed to Afghanistan when he was 19 so, he was no more than a kid then... as soon as I think anyone mentions patrol, my brother's face goes straight into that...he's completely messed up... and I think of children and I automatically think of my children.

For this ACO the 'personal,' involves the physicality of her 'brother's face' and her children. Her sisterly and maternal love misalign with comradely loyalty or lines of command. Despite the uncertainty of deliberation, she displays agency and responsibility for her actions:

[B]ut I would absolutely $110 \%$ like employ [sic. deploy].

Under war conditions, despite her multiple and incommensurable subject positions (parental and professional), she chooses the soldier-subject position to make an unequivocal decision.

Thus, the junior officer group displayed discourse and subject positions distinctively different from the higher ranks. To sum up, they revealed four important characteristics. First, the junior group explicitly incorporated values and morals in their responses. Their moral actions tended to align with their personal beliefs, not with ROEs. Although understanding the moral complexity, they did not resile from making a decision and displaying agency. Second, the junior officers understood the moral limitations of ROEs in practice. This is evident in this ACO's response:

[T] he rules state that I can do it, I'm not breaking any rules... I think just um, what is going to be harder for me, for myself would be the fact that I killed ah, school children through my actions or is it the fact that an Australian soldier died because of my inaction.

At the point of conation (carrying out an intention to act or not to act), this respondent displays a high level of moral agency. Analysis of junior officers' responses suggests that those who are most physically proximate are also more morally engaged.
This junior officer group were also more likely to resolve the moral dilemma by adopting a consequentialist ethical point of view. They tended to justify their actions in terms of trade-offs in which loyalty to comrades (a solidarity principle) is accorded the highest value. Yet it is not a callous calculation as their humanity is clearly evident. In response to the interviewer's suggestion that her biggest conflict was to go against her personal code of values and morals, this junior officer responded:

[I]t definitely does...there are rules of engagement and you're allowed to protect your team.....and you have solid intel and potentially you can justify taking out that threat...you really don't ever want to be in that scenario where you have to kill a child.

Third, this group identified the problem of being situationally aware in an uncertain environment. In the fog of war, information needed to make their judgment and to be situationally aware is invariably unclear:

[I]t is a very difficult question to answer with that limited information available. (Aircrew)

[I] suppose part of that is working out if you know really want... how many people are on either side. (PCO)

Finally, and more significantly, for some, the categories of friendlies or combatants became morally blurred when children were included in the scenario. This pilot quite clearly adopted an agentive values approach with a response that was the most unambiguous of all responses:

[I]f I had no time at all to make that decision I would absolutely not deploy weapons on a school ... if I knew full well that it was a school I was going to drop a weapon on and that there was a chance I was going to kill school children then I would absolutely not.

It was more evident that this group was more ethically and morally articulate in responding to the scenario. The junior officers were very conscious of the ramifications of their actions, and they needed to justify their actions primarily to themselves. Junior officers' high level of moral sensibility illustrates the tensions that may occur between following the rules and their innate moral compass and ethical conation.

\section{Discussion}

This paper investigated whether values-based leadership can be enacted in a rules-based organization. To answer this question we interviewed junior, senior, and executive officers in the Royal Australian Air Force seeking their response to several moral vignettes. Our discourse analysis of their responses revealed the fundamental dialectic between 
personal moral agency in opposition to organizational power and behavior codes, a dialectic that is likely to operate in similar ways in other kinds of organizations.

\section{Impediments to Enacting Values-Based Leadership}

It was evident within this study that leaders struggled with the moral concept of "values-based leadership". When making a moral choice, the presence of competing narratives became evident in lower ranks as their subject positions as the moral self, or for females, the subject position of mother and sister were explicitly articulated.

Values are not necessarily moral in nature, but are guiding principles explaining human decision-making, attitudes, and behaviors. Some values such as universalism and benevolence, however, have a moral dimension. Others are socially oriented (tradition, conformity, and security), while some express self-interest (power, achievement, hedonism, stimulation, self-direction). Thus, the enactment of values can produce contradiction and incommensurability within and between moral (e.g., benevolence) and non-moral (e.g., tradition, conformity) values. This was evident in the junior officers' struggles with the virtue of comrade loyalty and universalism/benevolence. Significantly, there is increasing cross-disciplinary interest in notions of character, virtue, traits and disposition (Miller et al., 2015; Piazza et al., 2014; Pizarro \& Tannenbaum, 2012).

\section{Dialectic: Individual Agency and Codes}

To act virtuously requires free will, which implies agency. Thomas Aquinas states that "free and responsible actions ... [are] internally caused by the wills of the agents themselves and not by causes external to the agent" (Kane, 2000, p. 75; see also Stump, 1990). However, our research shows that those with most power, the executive officers, drew on the discourse of codes, which enact ethical standards about appropriate behavior in particular situations. Forced compliance with ethical codes eliminates agency, the foundation of virtuous action. In other words, leadership virtue and ethics stand in a relationship of aporia, or "the ghost of the undecidable" (Derrida, 1992, p. 24). Simply put, some decisions are unresolvable because, according to Derrida, they are "puzzling moments of metaphysical statements that cannot be explained through regular logic"; they are "undecidable situations" and "incalculable" (Rasche, 2011, p. 257). At an organizational level, the truly ethical leader "must, somehow, negotiate a path between contradictory, irreconcilable, and incommensurable responsibilities and accountabilities" (McKernan, 2012, p. 259).

However, indeterminacy is unacceptable in a military organization, especially in combat. The most senior, most powerful executive officers, resolve this indeterminacy by drawing on a discourse of codes and processes, and remain mute on individual agency and enacted virtues. As tempting as it might be to cast these executive officers as villains, our discourse approach provides a more sophisticated and potentially useful understanding. That is, a virtue-based philosophy demands that the executive ranks must respect the agency of the junior ranks in making decisions in situations of high moral ambiguity provided it is informed by humane principles.

Though there was a significant representation of females participating in the study, there was not enough data to ascertain if gender was a relevant factor in relation to power. Generally, women participants were aligned with how the men responded; however more research is required to ascertain if there is any disparity or impact to relations of power that is gender specific.

\section{Conclusion}

This study provides a step towards understanding the challenges, tensions and contradictions in being able to enact values-based leadership in rules-based organizations that face significant risks and moral complexity. Our findings suggest that the core component that needs to be understood is the individual as a multiply constructed subject.

From a Foucauldian perspective, "to speak is to assume a subject position within a discourse and to become subjected to the power and regulation of that discourse" (Weedon, 1987, p. 116). Thus, we need to acknowledge the multiple subject positions apart from level of authority (in this study, rank). Notably, virtually no acknowledgment of subject position other than rank was evident in the executive officers. However, there was increasing recognition of multiple subject positions further down the ranks: as a medical or engineering professional, as a mother or sibling, for example. But ultimately the dominant subject position was one subordinate to military discursive regulation. In other words, the military organization had achieved the chief function of disciplinary regulation which is to train "the moving, confused, useless multitudes of bodies and forces into a multiplicity of individual elements" (Foucault, 1979, p. 170) to produce and maintain specific particular relations of power and social practices.

We have identified distinctive discursive markers of ranklevel subject positions. More specifically we have shown that executive officers are oriented by a bureaucratic code, the ethical compass of which is set by the panopticon of the public gaze on organizational reputation. This orientation creates a process that is slow, procedural, and technocratic. Because of its technocratic nature this discourse inevitably 'dehumanizes' by abstraction, categorization, and by procedure. While this does not necessarily reflect their moral 
probity-more so a consequence of the subject position they adopt-executive officers need to be deeply aware of this tendency if they are to truly generate virtuous organizations. The junior officer class, those containing officers most closely involved in combat, displayed distinctly different discursive patterns and greater agency. Their often-visceral responses contrast sharply with the detached abstraction of the executive officers. The junior officers were the only ones in this study who used the language of morality and ethics that related to their whole subject not just the military subject. It was they who acknowledged the aporia of the situation in which they were placed, characterized by dissonance with the formal codes. It was clear that, while respecting life as far as possible, the ultimate value they held was loyalty to their comrades. Thus, by maintaining this virtuous instinct in the junior officers, the executives should feel greater confidence that agentic moral decision-making will mostly lead to the right outcome.

\section{Implications and Future Research}

We have re-framed the call for 'values'-based leadership as a desire to cultivate virtue-based leadership. Virtue based leadership in the Aristotelian tradition rests on intellectual and moral virtues of individuals committed teleologically to eudaimonia, or human flourishing. That is, seeking the perfect good is self-sufficient so long as one is driven by a deep respect for humanity (McKenna \& Rooney, 2019). It is reasonable to assume that many bureaucracies (such as defence, hospitals, schools, law enforcement, government agencies), but also some large corporations, are altruistically motivated and characterized by identifiable values such as loyalty. Furthermore, although moral complexity and risk, and the potential to cause harm may be very different in non-military organizations, it remains a real possibility and potentially manifests in a range of ways. Psychological harm to employees, environmental harm, and economic harm are just three examples. Many participants also display the intellectual and moral virtues consistent with a humanitarian outlook. Yet, as we have seen, it is unclear which moral compass is used: public opinion and 'community values' or personal virtues. If rules-based organizations are truly committed to a change to virtuous leadership, our analysis suggests three topics for future research, the centrality of morality and virtue, leader character, and virtuous behavior.

In considering other military organizations around the world, who have adopted or attempted to adopt progressive cultural and leadership changes, the Scandinavian countries stand out. In Norway, for example, their approach has been guided by a politics of peace that is "somehow more desirable" (Gebhard, 2017, p. 254). Though rooted in the history of violence from the Norwegian Vikings as well as the "militant imperialism of seventeenth-century Sweden" (Fallan, 2015, p. 379), Scandinavian countries have shifted their national cultures significantly to have a decidedly social democratic values base emphasizing peace and equality, and advocating for a better way of living (Fallan, 2015).

Germany's approach to security and defence in relation to strategic culture change has undergone a significant transformation since World War II and its ensuing post-Cold War anti-militarism (Seppo \& Joja, 2019). From Holocaust studies and post-war evidence at Nuremberg, Germany reconsidered their policies and practices in relation to occupation and military campaigns (Melson, 2011). Germany's cultural transformation to one of military restraint illustrates what scholars such as Seppo and Joja (2019) argue is Germany's self-conception as a civil rather than military power. This view "aligns with the logic of friendship in a Kantian anarchy" that permeates German attitudes to the military (Seppo \& Joja, 2019, p. 389). Furthermore, they argue that Germany's role as a mediator within global conflicts aligns with this orientation (Seppo \& Joja, 2019).

The sheer force of cultural and political history and the underlying evolution of national cultures have made these European, as it were, non-militarizations of the military possible. The implication is that Germany's ethos, along with the Scandinavian countries, arises from a deeply held socially intelligent, authentic, and genuine morality that is axiomatic of their larger cultural and political histories which enables them to be exemplars in global politics, defence, and security. Although outside the scope of this study, an important research question that arises is how other nations, such as the US and Australia, who do not necessarily have the same kinds of history as Scandinavia and Germany, actively achieve this kind of progressive military and corporate leadership orientation?

\section{Clarifying Morality and Virtue in an Organizational Setting}

Day et al's (2014) review of leader development scholarship over 25 years makes no mention of morality or virtue. Rather, authentic leadership is understood in terms of follower trust and positive other-directed emotions that motivate leaders "to behave in ways that reflect self-transcendent values (e.g., honesty, loyalty, and equality)" (p. 65). Thus, it seems that leadership research is not providing much guidance for those who are truly motivated to create virtuous organizations. More recent literature has been more helpful. For example, Crossan et al., (2017, p. 988) state that a virtuous character is an amalgam of virtues, personality traits, and values that enable excellence. While certain personality traits are important in producing a dispositional orientation to positive forms of leadership such as transformational leadership, they are relatively stable (Bono \& Judge, 2004). 
However, because most virtues are not trait-based, there is significant potential to develop character (Crossan et al., 2017). Virtuousness in organizational settings goes beyond morality. Virtuousness produces human flourishing (Nussbaum, 1994) and ennobles humankind (Bright et al., 2014). It provides meaningful life purpose, transcendence, and resilience when facing challenges (Cameron et al., 2004). Thus, in pursuing and enacting virtue, a person not only does the right thing, but also ennobles themself and others while producing a more flourishing organization. In a defence (or police) force, the noble character is the person who deeply understands the awesome responsibility involved in taking another person's life or placing subordinates in mortal danger. Such an understanding comes initially from a deep respect for human life, but must also understand the sometimes blurred boundaries of good and evil in the context of contemporary warfare.

\section{Leader Character}

This research identified the potential morally conflictual nature of multiple subject positions. Each soldier has a unique narrative as a son or daughter, possibly is a parent, has networks of relationships of various strengths, and various skills including potentially professional status such as a doctor with its own ethical demands. This amalgam producing the individual is their habitus manifested in ways of doing, what Foucault unattractively calls technologies of the self (Collins, 2020; Foucault, 1978). We suggest future research consider the role of habitus in shaping the virtuous person. Throwing the conceptual net fairly wide, future research, influenced by the philosophical concept of askesis, or practices of the self, could consider how these might be used to develop wisdom, particularly its ethical dimension (Collins, 2020; Cooper, 2012; Hadot \& Davidson, 1995). This could involve repurposing these ancient techniques for virtuous leadership development. Indeed, renewed spiritual practices like meditation, contemplative practice, and so on can be reconceptualized and incorporated into a new leadership research agenda (see for example, King et al., 2020; Rooney et al., 2021; Flyvbjerg, 2001).

\section{Which Virtues?}

It is beyond the scope of this paper to define the appropriate organizational virtues in the armed forces, or any other organization. However, it is worthy of more analysis, discussion, and application. A starting point could be Hackett and Wang's (2012) list of four cardinal virtues drawn from Aristotle and Confucius, such as courage, temperance, and righteousness. As well, Peterson and Seligman's (2004) comprehensive review of the philosophy, psychology, sociology, religious, and historical literatures, identified 24-character strengths, clustered within six broad virtues (wisdom, courage, humanity, justice, temperance and transcendence).

\section{How can Organizations Promote Virtuous Leadership?}

If virtue-based leadership within organizations, particularly bureaucracies, is to be more than a rhetorical flourish, then their most senior of leaders need to commit themselves to a deep self-reflection on how their subject position limits virtue as well as analysis that draws on the literature of philosophy, psychology, and sociology to guide their deliberations. Of course, this is easier said than done but the foundations of a new approach to leadership virtue and leader character development exist and have existed in various forms for millennia (as we discuss immediately above). The challenge is to get on and do it, because it may not be as hard to do as we think. The global risk landscape and the need for more virtuous leaders and ethical business are not going to reduce in the foreseeable future. The imperative to shift leadership development and practice is clear.

\section{Appendix 1}

\section{Multi-Facetted Vignette}

The vignette needed to be relevant to each rank category for authenticity and integrity of the study. Figure 2 illustrates the how the vignette scenarios were provided to respondents. Each of the officer categories received the Air or Ground vignette scenario depending on their job category (e.g., aircrew or gound role). This vignette set the scene for all of the respondents. The Junior Offficers received the air or ground vignette and their own dilemma for them to respond to. The Senior Officers in addition to the air or ground vignette, received an added component which built onto the scenario that was relevant to being in unit command. As such, they received a different dilemma to respond to as a unit commander within the scenario. The Executive Officers received the air or ground vignette, the unit command scenario (Senior Officers) and then their own additional component that was relevant to them being senior command during operations. Similar to the other officer categories, the Executive Officers had their own dilemma based on their addition to the scenario. This was done to ensure relevance and authenticity to each rank category in these combat scenarios. Below is each of the vignette scenarios with the relevant dilemmas for each officer category. At the end are the discussion questions that were provided to all respondents. 
Fig. 2 Illustration of Vignette Dissemination to Respondents
MULTI-FACETTED VIGNETTE

\begin{tabular}{|l|l|l|l|}
\hline $\begin{array}{l}\text { Junior } \\
\text { Officer }\end{array}$ & $\begin{array}{l}\text { Air or } \\
\text { Ground } \\
\text { Vignette \& } \\
\text { Dilemma }\end{array}$ & \multicolumn{1}{|c|}{} \\
\hline $\begin{array}{l}\text { Senior } \\
\text { Officer }\end{array}$ & $\begin{array}{l}\text { Air or } \\
\text { Ground }\end{array}$ & $\begin{array}{l}\text { Unit Command } \\
\text { Vignette \& } \\
\text { Dilemma }\end{array}$ & \\
\hline $\begin{array}{l}\text { Executive } \\
\text { Officer }\end{array}$ & $\begin{array}{l}\text { Air or } \\
\text { Ground }\end{array}$ & Unit Command & $\begin{array}{l}\text { Senior } \\
\text { Vignette }\end{array}$ \\
& Vignette & $\begin{array}{l}\text { Commander } \\
\text { Vignette Addition } \\
\text { \& Dilemma }\end{array}$
\end{tabular}

\section{Air Mission}

\section{Junior Officer (Command Lead)}

You are flying a close air support mission over Iraq/Afghanistan/Syria/etc. You observe a heavily armed enemy insurgent group moving through a school with children present. They are loading a heavy machine gun on top of a school classroom, about to engage an Australian Army patrol walking down the road to the school. You have no communications with the patrol. If the insurgents commence firing, Australian soldiers will almost certainly be killed. The Rules of Engagement allow you to use deadly force to protect friendly forces.

\section{Ground Mission}

\section{Junior Officer (Command Lead)}

You are working from a forward air base, conducting an armed escort mission into the local town to receive supplies and urgently needed spare parts from a freight company. You observe an Australian Army patrol moving up the road towards the local school. You turn towards the school and observe ammunition being handed up to the roof of a classroom by a male dressed in a school teacher uniform with two teenagers standing next to him. He sees you and says something to the two boys who start running towards the Army patrol, one pulling out what appears to be a mobile phone. You have been told that local groups are using mobile phones to trigger Improvised Explosive Devices.

\section{Dilemma}

Do you use deadly force to neutralize the potential deadly threat to the Australian Army patrol? What are the personal and professional ramifications of taking the action you choose? How do you live with the thought that potentially innocent civilians, including children, might die? How do you live with the thought that potentially the lives of the Australian Army patrol might be lost?

\section{Senior Officer-Unit Command (From Either Vignette- Air or Ground)}

While possibly preventing the loss of Australian life, the actions of your member/s have resulted in the death of a teacher and at least two young children. The investigation has been conducted. The teacher and students were not armed, but one may have had a mobile phone ready to trigger an IED (the phone was destroyed so this is speculation). It is determined that Rules of Engagement did not provide sufficiently detailed guidance to deal with this scenario; Defence Legal advise it is at your discretion to send the member/s to a Court Martial.

\section{Dilemma}

Was deadly force to neutralize the armed enemy insurgent group/potential deadly threat warranted and justified? What are the personal and professional ramifications of the decision you choose? How do you justify your decision based on the loss of lives and the impact on the defence personnel who took the actions (i.e., Pilot/ACO/SEC/LOG/ENG member)? How do you want your decision to impact your future decision-making/what standard are you setting?

\section{Executive Officer-Command (From Either Vignette-Air or Ground)}

The unit commander decides NOT to prosecute the members. However, this is now the third case in the last four months where civilian deaths have not been examined in a robust legal proceeding, and public sentiment in Australia is wavering in support for the military campaign. A journalist embedded with the Army formation is agitating for information on the circumstances of the deaths to be made public. The member is beginning to show serious mental health issues from the actions they took, and you 
are advised by Medical that a public release of their names will cause further injury.

\section{Dilemma}

Was the decision of the unit commander warranted and justified? Should public opinion be used as part of your decision-making process and how you conduct any investigation? What are the personal and professional ramifications of the decision you choose? How do you justify your decision based on the loss of lives and the impact on the personnel who took the actions (i.e., Pilot/ACO/SEC/ LOG/ENG member)? How do you want that to impact your future decision-making/what standard are you setting?

\section{All Respondents Were Asked}

Discussion: What leadership/decision-making approach do you apply in this situation? What training, education, development or experiences did you draw on to answer this dilemma? In answering this scenario, were there any conflicts or challenges you believe you faced in making the decision (personal and/or professional).

Author Contribution The conceptualization of this article is based primarily on the first study from Kate Robinson's doctoral thesis. Material preparation, data collection and initial analysis were performed by KR. $\mathrm{BM}$ and DR contributed to the theoretical orientation and approach of the study. BM and DR engaged in the second state analysis of the data with all authors engaged in the iterative revision and proof reading of the manuscript. All authors read and approved the final manuscript

Funding The authors have no relevant financial or non-financial interests to disclose.

\section{Declarations}

Conflict of interest The authors have no conflicts of interest to declare that are relevant to the content of this article. All authors certify that they have no affiliations with or involvement in any organization or entity with any financial interest or non-financial interest in the subject matter or materials discussed in this manuscript. The authors have no financial or proprietary interest in any material discussed in this article.

Ethical Approval Ethical approval were gained from both the University of Queensland (Clearance Number 152201) and Australian Department of Defence (Defence Protocol Number: DPR-LREP 026/16) to conduct the research interviews. Information sheets were provided to and consent forms were received from all participants in the study. This study adhered to the guidelines of the ethical review process of The University of Queensland and the National Statement of Ethical Conduct in Human Research.

\section{References}

Abdelnour, S., Hasselbladh, H., \& Kallinikos, J. (2017). Agency and institutions in Organization Studies. Organization Studies, 38(12), 1775-1792.

Alvesson, M. (2003). Beyond neopositivists, romantics, and localists: A reflexive approach to interviews in organizational research. The Academy of Management Review, 28(1), 13-33.

Archer, M. S. (2003). Structure, Agency, and the Internal Conversation. Cambridge University Press.

Bartels, D. M., Bauman, C. W., Cushman, F. A., Pizarro, D. A., \& McGraw, A. P. (2015). Moral judgment and decision making. In G. Keren \& G. Wu (Eds.), The Wiley Blackwell Handbook of Judgment and Decision Making (pp. 478-515). Wiley.

Bass, B., \& Avolio, B. (1990). The implications of transactional and transformational leadership for individual, team, and organizational development. Research in Organizational Change and Development, 4(1), 231-272.

Bell, A. (2011). Re-constructing Babel: Discourse analysis, hermeneutics and the interpretive arc. Discourse Studies, 13(5), 519-568.

Bono, J. E., \& Judge, T. A. (2004). Personality and transformational and transactional leadership: A meta-analysis. Journal of Applied Psychology, 89(5), 901-910.

Boudon, R. (Ed.). (2001). The Origin of Values: Essays in the Sociology and Philosophy of Beliefs. Transaction Publishers.

Bright, D. S., Winn, B. A., \& Kanov, J. (2014). Reconsidering virtue: Differences of perspective in virtue ethics and the positive social sciences. Journal of Business Ethics, 119(4), 445-460.

Buchanan, D. A., \& Hällgren, M. (2019). Surviving a zombie apocalypse: Leadership configurations in extreme contexts. Management Learning, 50(2), 152-170.

Burkitt, I. (2016). Relational agency: Relational sociology, agency and interaction. European Journal of Social Theory, 19(3), 322-339.

Cameron, K. S., Bright, D., \& Caza, A. (2004). Exploring the relationships between organizational virtuousness and performance. American Behavioral Scientist, 47(6), 766-790.

Cameron, K. S., \& Quinn, R. E. (2011). Diagnosing and changing organizational culture based on the competing values framework (3rd ed.). Jossey-Bass.

Casey, C. (1999). "Come, join our family": Discipline and integration in corporate organizational culture. Human Relations(New York), 52(2), 155-178.

Cavana, R. Y., Sekaran, U., \& Delahaye, B. L. (2001). Applied business research: qualitative and quantitative methods (Australian). Wiley.

Collins, S. (2020). Wisdom as a Way of Life: Theravāda Buddhism Reimagined. Columbia University Press.

Coole, D. (2007). Experiencing discourse: Gendered styles and the embodiment of power. British Journal of Politics and International Relations, 9(3), 413-433.

Cooper, J. M. (2012). Pursuits of wisdom: Six ways of life in ancient philosophy from Socrates to Plotinus. Princeton University Press.

Crossan, M. M., Byrne, A., Seijts, G. H., Reno, M., Monzani, L., \& Gandz, J. (2017). Toward a framework of leader character in organizations. Journal of Management Studies, 54(7), 986-1018.

Day, D. V., Fleenor, J. W., Atwater, L. E., Sturm, R. E., \& McKee, R. A. (2014). Advances in leader and leadership development: A review of 25 years of research and theory. The Leadership Quarterly, 25(1), 63-82.

Derrida, J. (1992). Force of Law: The 'Mystical foundation of authority. In D. Cornell, M. Rosenfeld, \& D. G. Carlson (Eds.), Deconstruction and the Possibility of Justice (pp. 3-67). Routledge.

Emirbayer, M., \& Mische, A. (1998). What is agency? American Journal of Sociology, 103(4), 962-1023. 
Endsley, M. R. (1988). Design and evaluation for situation awareness enhancement. Proceedings of the Human Factors Society Annual Meeting, 32(2), 97-101.

Fallan, K. (2015). Nordic noir: Deadly design from the peacemongering periphery. Design and Culture, 7(3), 377-402.

Fisher, K., Hutchings, K., \& Sarros, J. C. (2010). The "bright" and "shadow" aspects of in extremis leadership. Military Psychology, 22(S1), S89-S116.

Flyvbjerg, B. (2001). Making social science matter: Why social inquiry fails and how it can succeed again. Cambridge University Press.

Foucault, M. (1971). Orders of discourse. Social Science Information, $10(2), 7-30$.

Foucault, M. (1978). Governmentality. In G. Burchell, C. Gordon, \& P. Miller (Eds.), The Foucault Effect: Studies in Governmentality (pp. 87-10). Univeristy of Chicago Press.

Foucault, M. (1979). Discipline and punishment: The birth of the prison. Vintage Books.

Foucault, M. (1982). The subject and power. Critical Inquiry, 8(4), $777-795$.

Foucault, M. (1989). Power affects the body. In M. Foucault (Ed.), Foucault Live: Interviews 1961-1984 (pp. 207-213). Semiotext(e).

Fraher, A., \& Grint, K. (2018). Agonistic governance: The antinomies of decision-making in US Navy SEALs. Leadership, 14(4), 395-414

Galusca, A., Circiu, I., \& Boscoianu, M. (2010). Review of models and analytic instruments in operational military decision making process. Journal of Defense Resources Management, 1(1), 93-100.

Gardner, W. L., Cogliser, C. C., Davis, K. M., \& Dickens, M. P. (2011). Authentic leadership: A review of the literature and research agenda. The Leadership Quarterly, 22(6), 1120-1145.

Gebhard, C. (2017). Scandinavian defence and alliance policies: different together. In Peter Nedergaard, Anders Wivel, Peter Nedergaard, \& Anders Wivel (Eds.), The Routledge handbook of Scandinavian politics (pp. 254-26). Routledge.

Gerdes, K. E., \& Stromwall, L. K. (2008). Conation: A missing link in the strengths perspective. Social Work, 53(3), 233-242.

Giddens, A. (1979). Central problems in social theory: Action, structure, and contradiction in social analysis, 241. University of California Press.

Giddens, A. (1984). The constitution of society: Outline of the theory of structuration. Polity.

Graham, J., Nosek, B. A., Haidt, J., Iyer, R., Koleva, S., \& Ditto, P. H. (2011). Mapping the moral domain. Journal of Personality and Social Psychology, 101(2), 366-385.

Gregory, R. J. (2014). Psychological testing: History, principles, and applications (7th ed.). Pearson Education.

Hackett, R. D., \& Wang, G. (2012). Virtues and leadership. Management Decision, 50(5), 868-899.

Hadot, P., \& Davidson, A. I. (1995). Philosophy as a way of life: Spiritual exercises from Socrates to Foucault. Blackwell.

Haidt, J. (2001). The emotional dog and its rational tail: A social intuitionist approach to moral judgment. Psychological Review, 108(4), 814-834.

Hannah, S. T., Avolio, B. J., \& May, D. R. (2011). Moral maturation and moral conation: A capacity approach to explaining moral thought and action. Academy of Management Review, 36(4), 663-685.

Hannah, S. T., Uhl-Bien, M., Avolio, B. J., \& Cavarretta, F. L. (2009). A framework for examining leadership in extreme contexts. The Leadership Quarterly, 20(6), 897-919.

Hartman, E. M. (2007). Socratic questions and Aristotelian answers: A virtue-based approach to business ethics. Journal of Business Ethics, 78(3), 313-328.

Heracleous, L. (2006). A tale of three discourses: The dominant, the strategic and the marginalized. Journal of Management Studies, 43(5), 1059-1087.
Hudson, L. A., \& Ozanne, J. L. (1988). Alternative ways of seeking knowledge in consumer research. Journal of Consumer Research, 14(4), 508-521.

Hughes, R., \& Huby, M. (2012). The construction and interpretation of vignettes in social research. Social Work and Social Sciences Review, 11(1), 36-51.

Kaber, D. B., \& Endsley, M. R. (1997). Out-of-the-loop performance problems and the use of intermediate levels of automation for improved control system functioning and safety. Process Safety Progress, 16(3), 126-131.

Kane, R. (2000). The dual regress of free will and the role of alternative possibilities. Philosophical Perspectives, 14, 57-79.

King, E., Norbury, K., \& Rooney, D. (2020). Coaching for leadership wisdom. Organizational Dynamics.

Kolditz, T. A., \& Brazil, D. M. (2005). Authentic leadership in in extremis settings: A concept for extraordinary leaders in exceptional situations. Monographs in Leadership and Management, $3,345-356$

Križ, K., \& Skivenes, M. (2013). Systemic differences in views on risk: A comparative case vignette study of risk assessment in England, Norway and the United States (California). Children and Youth Services Review, 35(11), 1862-1870.

Lameck, W. U. (2013). Sampling design, validity and reliability in general social survey. International Journal of Academic Research in Business and Social Sciences, 3(7), 212-218.

Leder, J., Häusser, J. A., \& Mojzisch, A. (2015). Exploring the underpinnings of impaired strategic decision-making under stress. Journal of Economic Psychology, 49, 133-140.

Leximancer Manual (Version 3). (2008). Leximancer: The why, not just the what. Leximancer.

Mah, C. L., Taylor, E., Hoang, S., \& Cook, B. (2014). Using vignettes to tap into moral reasoning in public health policy: Practical advice and design principles from a study on food advertising to children. American Journal of Public Health, 104(10), $1826-1832$.

McAdams, D. P. (1996). Personality, modernity, and the storied self: A contemporary framework for studying persons. Psychological Inquiry, 7(4), 295-321.

McKenna, B., \& Graham, P. (2000). Technocratic discourse: A primer. Journal of Technical Writing and Communication, 30(3), 223-251.

McKenna, B., \& Rooney, D. (2019). Wise leadership. In R. Sternberg \& J. Bluck (Eds.), The Cambridge Handbook of Wisdom (pp. 649-675). Cambridge Universty Press.

McKenna, B., \& Waddell, N. (2006). Technologizing inhumanity: A discursive practice. Critical Discourse Studies, 3(2), 211-228.

McKernan, J. F. (2012). Accountability as aporia, testimony, and gift. Critical Perspectives on Accounting, 23(3), 258-278.

Melson, C. D. (2011). German counter-insurgency revisited. The Journal of Slavic Military Studies, 24(1), 115-146.

Miller, C. B., Furr, R. M., Knobel, A., \& Fleeson, W. (2015). Character: New directions from philosophy, psychology, and theology. Oxford University Press.

Nussbaum, M. (1994). The therapy of desire: Theory and practice in Hellenistic ethics. Princeton University Press.

Paarlberg, L. E., \& Lavigna, B. (2010). Transformational leadership and public service motivation: Driving individual and organizational performance. Public Administration Review, 70(5), 710-718.

Peterson, C., \& Seligman, M. E. P. (2004). Character strengths and virtues: A handbook and classification. American Psychological Association; Oxford University Press.

Piazza, J., Goodwin, G. P., Rozin, P., \& Royzman, E. B. (2014). When a virtue is not a virtue: Conditional virtues in moral evaluation. Social Cognition, 32(6), 528-558. 
Pizarro, D. A., \& Tannenbaum, D. (2012). Bringing character back: How the motivation to evaluate character influences judgments of moral blame. In M. Mikulincer \& P. R. Shaver (Eds.), The Social Psychology of Morality: Exploring the Causes of Good and Evil (pp. 91-108). American Psychological Association.

Putnam, L. L. (2015). Unpacking the dialectic: Alternative views on the discourse-materiality relationship. Journal of Management Studies, 52(5), 706-716.

Rasche, A. (2011). Organizing Derrida organizing: Deconstruction and organization theory. In A. Rasche (Ed.), Philosophy and Organization Theory (pp. 251-280). Emerald Group Publishing Limited.

Reed, G. S., Petty, M. D., Jones, N. J., Morris, A. W., Ballenger, J. P., \& Delugach, H. S. (2016). A principles-based model of ethical considerations in military decision making. The Journal of Defense Modeling and Simulation: Applications, Methodology, Technology, 13(2), 195-211.

Rooney, D., Küpers, W., Pauleen, D., \& Zhuravleva, E. (2021). A developmental model for educating wise leaders: The role of mindfulness and habitus in creating time for embodying wisdom. Journal of Business Ethics, 170(1), 181-194.

Ryus, C., \& Baruch, J. (2018). The duty of mind: Ethical capacity in a time of crisis. Disaster Medicine and Public Health Preparedness, 12(5), 657-662.

Sandberg, J. (2005). How do we justify knowledge produced within interpretive approaches? Organizational Research Methods, 8(1), 41-68.

Schwartz, S. (1992). Universals in the content and structure of values: Theoretical advances and empirical tests in 20 countries. Advances in Experimental Social Psychology (Vol. 25, pp. 1-65). Academic Press.

Schwartz, S. (2007). Universalism values and the inclusiveness of our moral universe. Journal of Cross-Cultural Psychology, 38(6), 711-728.

Seppo, A., \& Joja, I.-S. (2019). The struggle of a Kantian power in a Lockean world - German leadership in security and defence policy. Defense \& Security Analysis, 35(4), 384-405.
Smithson, J. (2000). Using and analysing focus groups: Limitations and possibilities. International Journal of Social Research Methodology, 3(2), 103-119.

Starcke, K., Polzer, C., Wolf, O. T., \& Brand, M. (2011). Does stress alter everyday moral decision-making? Psychoneuroendocrinology, 36(2), 210-219.

Stump, E. (1990). Intellect, will, and the principle of alternate possibilitys. In E. Stump (Ed.), Perspectives on Moral Responsibility. Cornell University Press.

Sweeney, P. J., \& Fry, L. W. (2012). Character development through spiritual leadership. Consulting Psychology Journal: Practice and Research, 64(2), 89-107.

Trevino, L. K. (1986). Ethical decision making in organizations: A person-situation interactionist model. Academy of Management Review, 11(3), 601-617.

Tripodi, P., \& Wolfendale, J. (2012). New wars and new soldiers: Military ethics in the contemporary world. Ashgate Publishing.

Weedon, C. (1987). Feminist practice and poststructuralist theory. Basil Blackwell.

Wendt, A. (1999). Social theory of international politics. Cambridge University Press.

Widdowson, H. G. (1995). Discourse analysis: A critical view. Language and Literature, 4(3), 157-172.

Widdowson, H. G. (1998). The theory and practice of critical discourse analysis. Applied Linguistics, 19(1), 136-151.

Wodak, R., \& Meyer, M. (2009). Methods of critical discourse analysis (2nd ed.). SAGE.

Publisher's Note Springer Nature remains neutral with regard to jurisdictional claims in published maps and institutional affiliations. 